\title{
Parents: RSV is Still Around, Trust Me
}

Gloria Wai Chung Li, MD

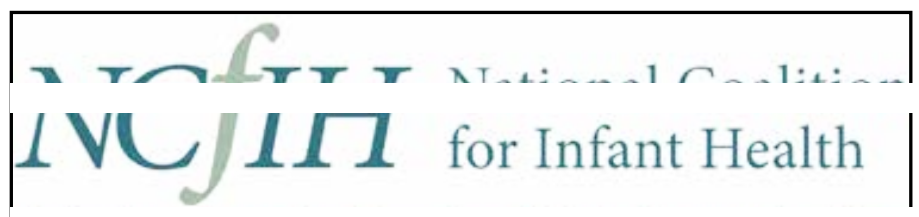

The National Coalition for Infant Health is a collaborative of more than 200 professional, clinical, community health, and family support organizations focused on improving the lives of premature infants through age two and their families. NCfIH's mission is to promote lifelong clinical, health, education, and supportive services needed by premature infants and their families. NCfIH prioritizes safety of this vulnerable population and access to approved therapies.

In June of this year, at age two, my daughter, Aria, was sent home from daycare with a high fever. Her pediatrician was concerned and prescribed an antibiotic for bacterial pneumonia. A COVID-19 swab was obtained - negative. Yet after a few days, she still wasn't getting better. In fact, she was getting worse.
Her breathing was getting more labored with audible wheezing. She became exhausted as every ounce of energy was used to maintain her breath. My husband commented that Aria was acting like her older brother did when he had Respiratory Syncytial Virus, commonly known as RSV, at ten months old.

I brought her back to her pediatrician, then urgently to the hospital. In the emergency room, she was immediately put on oxygen and was swabbed for COVID-19 and RSV. Her COVID-19 test was negative. Her RSV test, however, was positive.

By the time it came back, she was already in intensive care. We had been here before. In fact, Aria was born prematurely at 24 weeks and spent her first five months in the NICU, so we knew the chaos of alarms and flashing monitors.

The hardest part was seeing her struggle, but she was older this time, more aware that she was ill, more aware of her surroundings, and more easily scared. Watching your child struggle to fight a viral infection that no one - including myself - initially suspected was defeating as a parent.

Her doctors explained RSV in the summer is unusual. They hardly look for it during warmer months. This past winter was particularly unusual as RSV cases were at an all-time low. This is a result of the precautions taken for COVID-19.

I'm thankful Aria got better with high flow oxygen and that she

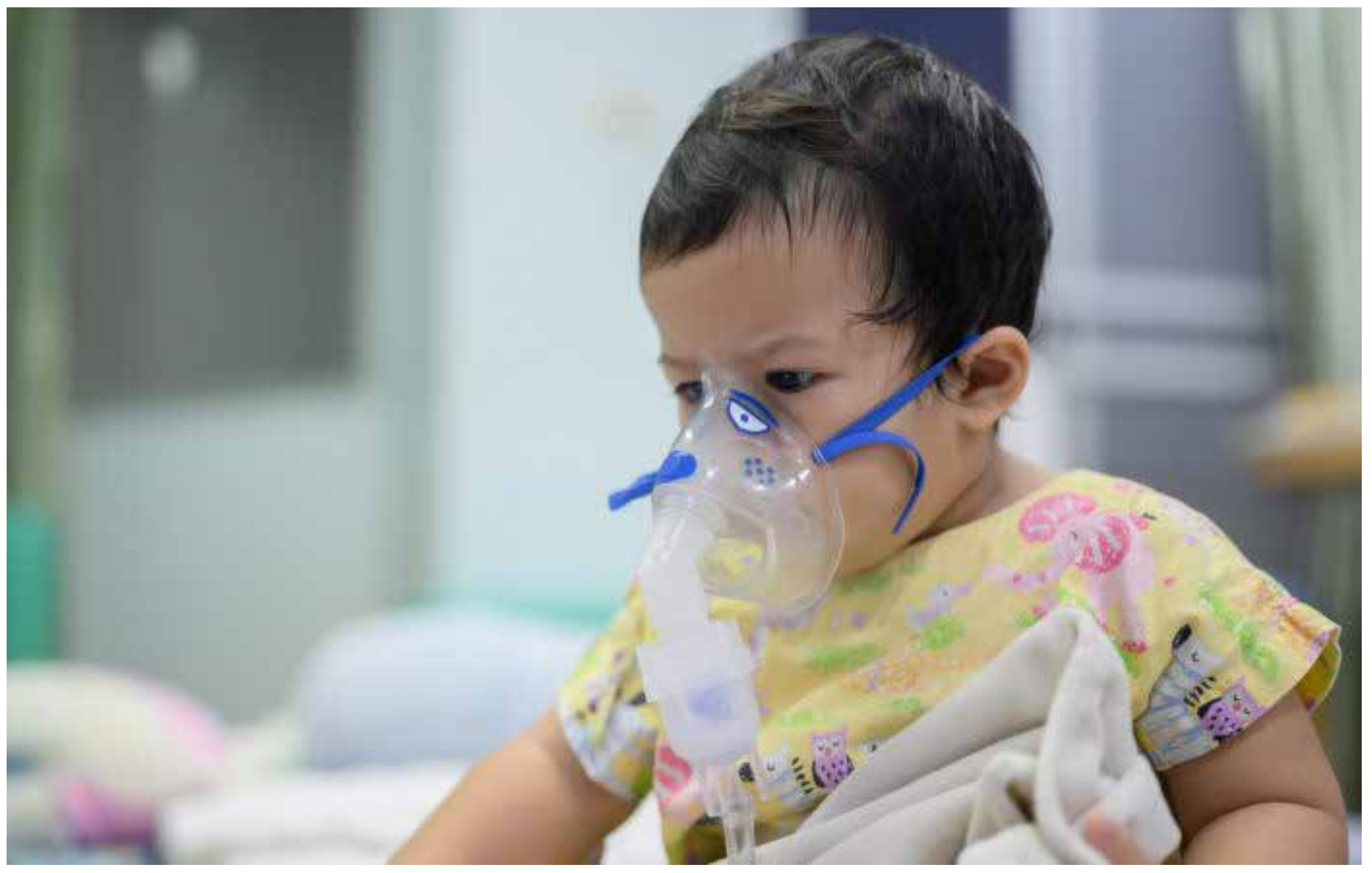


turned around before needing ventilator support.

But for countless other children out there like her, l'd like to see RSV testing become more immediate. We could have avoided a lot of pain and frustration had she been tested for RSV the first time she was presented with a high fever.

I would also like to see more children have the chance to ward off RSV before it starts. RSV is dangerous but treatable, even preventable, through a medication known as palivizumab. Aria was too old to qualify for it the year she landed in the hospital, but it's easy to see how she may have benefitted. Other kids like Aria deserve more protection, too.

So, as RSV season sets in, parents and health care providers should be vigilant about testing for RSV. It's a simple swab that could save your child and family from unnecessary suffering.

Disclosure: No relevant disclosures noted

NT
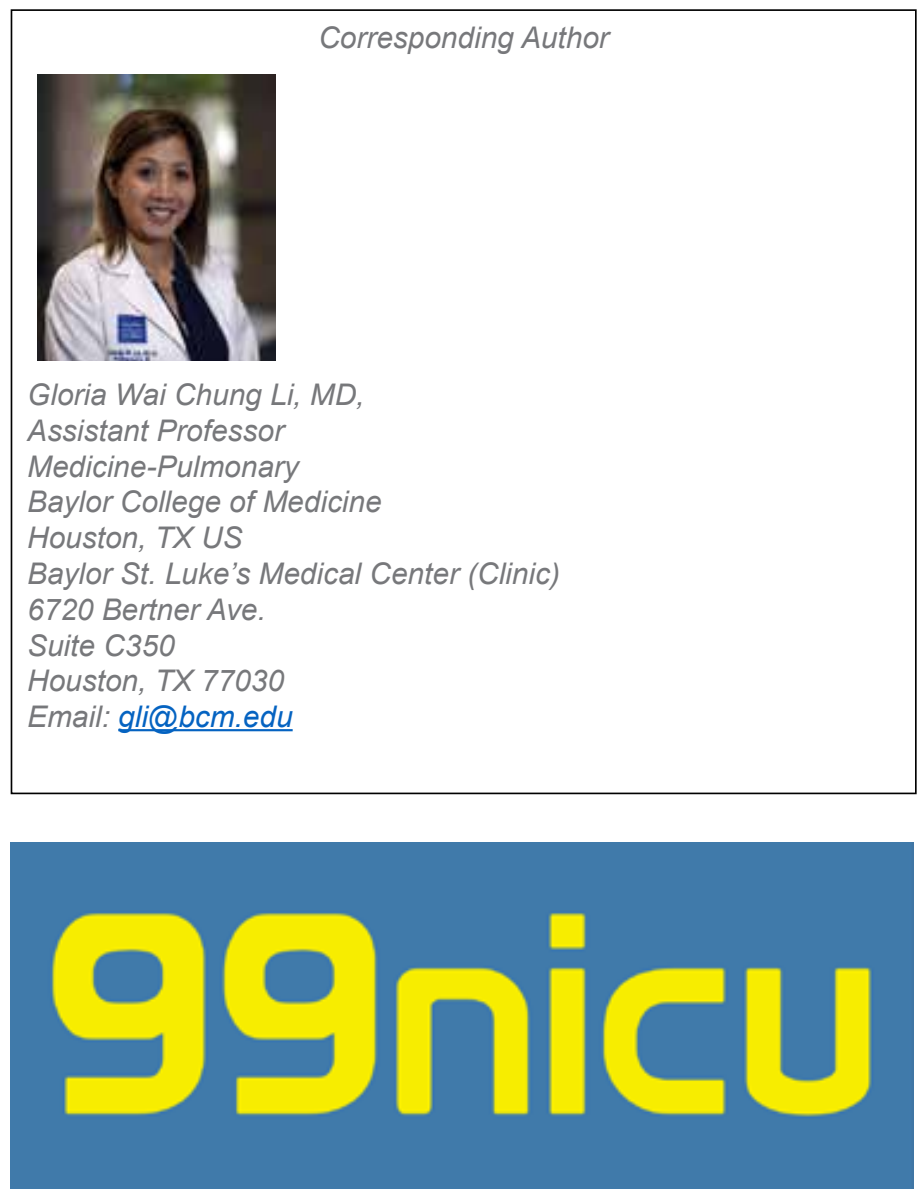

\section{National Coalition for Infant Health Values (SANE)}

Safety. Premature infants are born vulnerable. Products, treatments and related public policies should prioritize these fragile infants' safety.

Access. Budget-driven health care policies should not preclude premature infants' access to preventative or necessary therapies.

Nutrition. Proper nutrition and full access to health care keep premature infants healthy after discharge from the NICU.

Equality. Prematurity and related vulnerabilities disproportionately impact minority and economically disadvantaged families. Restrictions on care and treatment should not worsen inherent disparities.
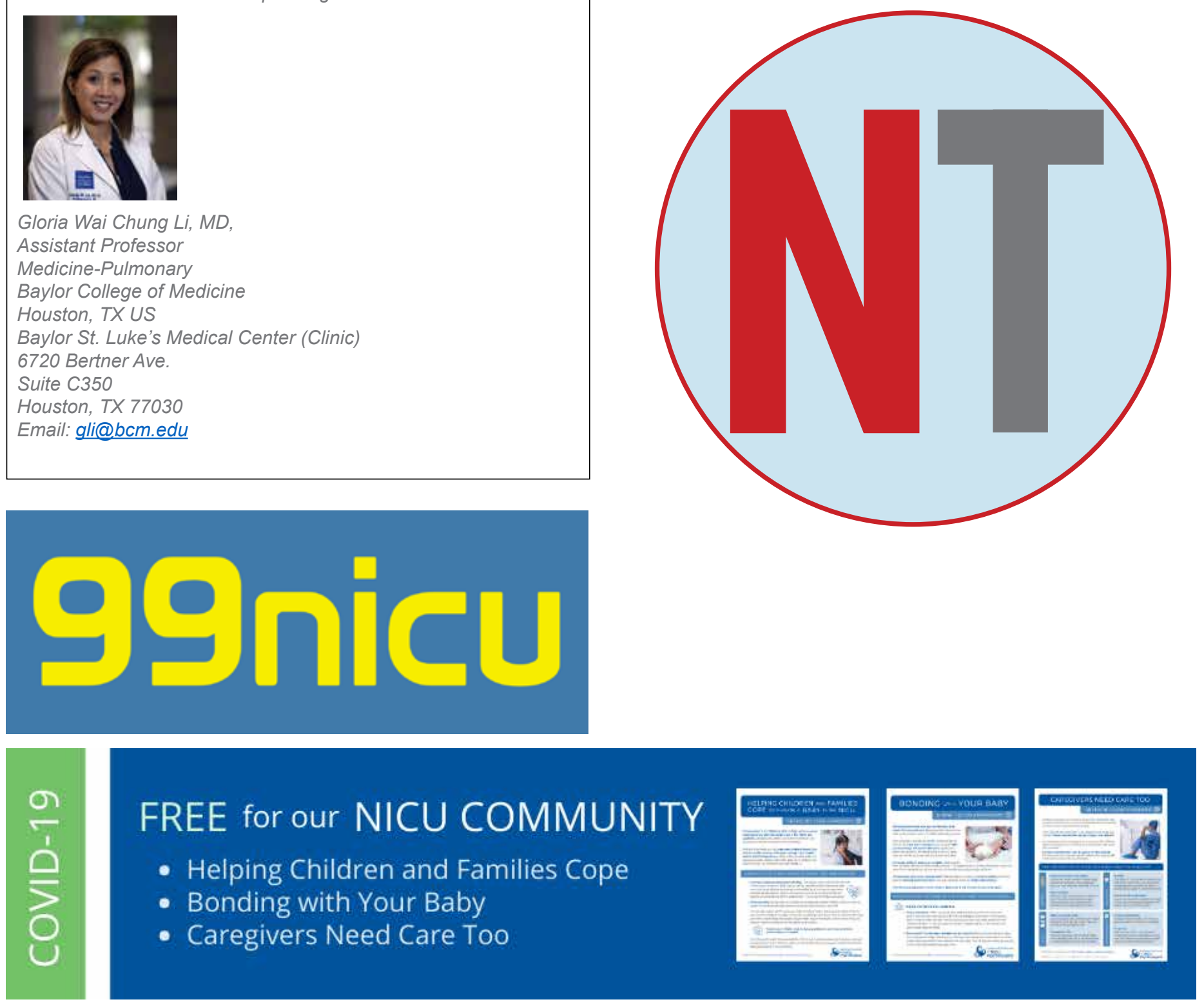